\title{
Aşağı Pasinler Ovası Sulama Şebekesinin Performansının (2012-2016) Değerlendirilmesi
}

\author{
Fatih Mehmet KIZILOĞLU ${ }^{1 *}$, Üstün ŞAHİN ${ }^{1}$, Serap DİLER ${ }^{1}$, Talip ÇAKMAKCI ${ }^{2}$ Semih $^{1}$ \\ ÖZTAŞKIN ${ }^{1}$
}

\author{
${ }^{1}$ Atatürk Üniversitesi, Ziraat Fakültesi, Tarımsal Yapılar ve Sulama Bölümü, 25240 Erzurum, Türkiye \\ ${ }^{2}$ Van Yüzüncü Y1l Üniversitesi, Ziraat Fakültesi, Biyosistem Mühendisliği Bölümü, 65080 Van, Türkiye \\ *e-mail: kiziloglu@atauni.edu.tr
}

\begin{abstract}
Öz: Sulama şebekelerinde performansın düşük olması; bitkisel üretimde kayıplara ve sürdürülebilir sulama alanlarında daralmalara yol açabilmektedir. Sınırlı su kaynaklarını bitkisel üretimde artış sağlayarak ekonomik faydaya dönüştürmeyi amaçlayan sulama yatıımlarından beklenilen yararın sağlanıp sağlanamadığının göstergeleri sulama şebekelerinin performanslarının izleme ve değerlendirme parametreleridir. Bu araştırma; Aras Sulama Birliği tarafından yönetilen Aşağı Pasinler Ovası sulama şebekesinin 2012-2016 yılları arasındaki sulama sistem performansının değerlendirilmesi amacıyla yürütülmüştür. Araştırma sonucunda 2012-2016 yıllarında sulamaya açılmış olan brüt 4610 ve net 3900 hektarlık alan için yıllık net su temin oranının 5.25 ile 10.68 arasında olduğu, yıllık toplam su temin oranının ise 2.23 ile 4.54 arasında değiştiği belirlenmiş̧ir. Sürdürülebilir sulama alanı oranı $\% 25,64$ ile \% 51.28 arasında gerçekleşmiştir. Bu yıllardaki üretim değeri oranları \% 15.20 ile \% 38.48 arasında olup karlılık oranı değerleri -0.11 ile 9.32 gibi çok geniş aralıklarda değişmiştir. Mali etkinlik oranı \% 5.66 ile \% 87.36 arasında, mali yeterlilik oranının 0.96 ile 4.72 arasında olduğu, tahsilat oranının \% 29.70-100 arasında gerçekleştiği belirlenmiştir.
\end{abstract}

Anahtar kelimeler: Performans göstergesi, Sulama birliği, Sulama sistem performansı, Sulama sistem verimliliği

\section{Evaluation of Irrigation Scheme Performance of Asagi Pasinler Plain (2012-2016)}

\begin{abstract}
Undesirable levels of system performance in the irrigation project areas may lead to crop production losses and a decrease in sustainable irrigation area. Whether or not the expected benefits of irrigation investments aimed at transforming limited water resources into economic benefits by providing an increase in crop production can be understood from the monitoring and evaluation results of irrigation performances. This research was conducted to evaluate the irrigation system performance of Asagi Pasinler Plain irrigation project area which is managed by the Aras Irrigation Association between 2012 and 2016. As a result of the survey, it was determined that the annual net water supply ratio for the area of total 4610 and net 3900 hectares opened for irrigation in 2012-2016 is between 5.25 and 10.68 and the annual total water supply ratio varies between 2.23 and 4.54 . Sustainable irrigation area ratio was between $25.64 \%$ and $51.28 \%$. The production rate ratios in these years are between $15.20 \%$ and $38.48 \%$, and the profitability ratios have changed over a very wide range from -0.11 to 9.32 . The financial efficiency ratio is between $5.66 \%$ and $87.36 \%$, the financial adequacy ratio is between 0.96 and 4.72 , and the collection rate is between $29.70 \%$ and $100 \%$.
\end{abstract}

Keywords: Performance indicator, Irrigation association, Irrigation system performance, Productivity of irrigation system, Benchmarking

\section{Giriş}

Türkiye, nüfus artış hızı bakımından dünyada ön sıralarda yer almakta ve bu durum çeşitli sosyal-ekonomik sorunları beraberinde getirmektedir. Söz konusu problemlerin çözümünde kişi başına milli gelirin artırılması ve gıda güvenliğinin sağlanması önemli rol oynar. Artan nüfusun gereksinimleri ve yaşam standardının yükseltilebilmesi için tarıma ayrılan kaynakların daha etkin biçimde değerlendirilmesi ve toprak-su kaynaklarının daha rasyonel kullanılarak birim alandaki üretimin artırılması gereklidir (Kızıloğlu 2002; Uçar 2010). Ülkemizde toprak ve su kaynaklarının geliştirilmesi amacıyla çeşitli projeler hazırlanarak uygulanmakta olup bunların başında sulama ve arazi ıslahı projeleri gelmektedir. Bu uygulamaların temel hedefi sulu tarıma geçişle birlikte tarımsal alanlardaki üretim değeri büyüklüğünü artırmak ve çiftçi gelirini en üst düzeye çıkarmaktır (Beyribey 1997). 
Sulama projelerinde, su kaynağının yeterli olması ve etkin kullanılması birim alandaki bitki verimi ile toplam alandan elde edilen geliri artırmakta, gereğinden fazla su kullanımı da drenaj ve tuzluluk gibi sorunları ortaya çıkarmaktadır (Molden ve Gates 1990).

Sulu tarımda başarının sağlanabilmesi toprak-su kaynaklarının etkin kullanımına bağlı olup bu amaçla izleme ve değerlendirme çalışmalarına ağırlık verilerek şebekelerde sistem performansı ölçmenin önemi giderek artmaktadır. Sulama sistemlerinin performansından kasıt planlamadaki hedeflere ulaşabilme oranıdır. Sulama şebekelerinin izleme ve performansının değerlendirilmesinde yeterlilik, güvenilirlik, eşitlik ve değişkenlik gibi parametreler kullanılmaktadır (Kızıloğlu 2002). Molden ve Gates (1990) 'de sulama projelerinde, su kaynağının yeterli olması ve etkin kullanılması koşuluyla birim alandan elde edilecek verim ile toplam alandan elde edilen gelirin artırılabileceğini vurgulamaktadırlar. Araştırmacılar ve su kullanıcıları daha iyi yönetim politikalarının oluşturulması amacıyla şebekelerde sulama performanslarının belirlenerek sonuçlarının geleceğe aktarılması çalışmalarının önemi giderek artmaktadır.

İyi planlanmış ve etkin işletilen sulama şebekelerinde, başta sulama suyu olmak üzere diğer bitkisel üretim girdilerinin de etkin kullanılmasıyla yüksek gelir sağlayabilmek mümkündür. Proje alanlarında doğru yer, zaman ve uygun miktarda dağıtımı yapılamayan sulama suyundan beklenilen yararın sağlanabilmesi güçtür. Bu nedenle fiziksel alt yapının iyi planlanması ve inşası şebeke yönetim planlarına da bağlı olarak başarıyı olumlu etkileyebilmektedir. Suyun etkin kullanımını sağlayarak elde edilecek geliri en yüksek düzeye çıkaracak, uygun optimizasyon tekniklerinin kullanımı yararlı olabilmektedir (Kızıloğlu 2002; Delibaş 1992).

Su kullanım etkinliğinin belirlenmesinde performans göstergesi olarak su sağlama oranını kullanan Rao (1993), şebekeye saptırılan suyun şebekenin sulama suyu gereksinimine oranı olan bu değerlerin haftalık, aylık ve sezonluk hesaplanabileceğini belirtmiş̧tir. Su sağlama oranı denilince, toplam sulama alanı içerisinde optimum bitki deseni için teorik su sağlama oranı ve gerçekleşen bitki dağılımına göre ise gerçek su sağlama oranı akla gelmektedir. Net gereksinime göre su sağlama oranının 2.50 'den büyük olması şebekede uygun bir su dağılımının olduğunu göstermektedir (Kızıloğlu 2002; Çakmak 1994).

Beyribey (1989) ise Konya-Alakova yeraltı suyu işletmesinde dağıtım ve kullanım etkinliğini belirlemek amacıyla yaptığı çalışmada, sulama sistem performansını fiziksel etkinlik, tarımsal etkinlik, ekonomik etkinlik ve su dağıtım etkinliği şeklinde sınıflandırmıştır.

Çakmak (1994), Konya Çumra sulama şebekesinde su dağıtım ve kullanım etkinliğini belirlemek amacıyla yapmış olduğu çalışmada, sulama sistem performansını fiziksel etkinlik, tarımsal etkinlik, yöntem etkinliği ve ekonomik etkinlik konuları altında incelemiştir. Çalışmada belirlenen göstergeler; iletim, dağıtım ve su uygulama randımanı, su dağıtım performansı, sulama zamanı, optimum bitki dağılımı, sulama oranı, fayda - masraf oranı ve tahsilat oranıdır.

Beyribey ve ark. (1995), ülkemizde devlet sulama şebekelerinde uygulanan izleme ve değerlendirme sistemini inceledikleri çalışmada, izleme ve değerlendirme kavramları üzerinde durmuşlar ve DSI'nin değerlendirme çalışmalarında tarımsal etkinlik göstergelerinin yeterli; su kullanım, ekonomik, sosyal ve çevresel etkinlik göstergelerinin yetersiz olduğunu belirtmiş̧lerdir.

Beyribey ve Tatlıdil (1997), Ereğli - İvriz Sağ Sahil Sulama Birliğinde sulama sistem performansını değerlendirmek amacıyla yaptıkları araştırmada, su sağlanması, su kullanımı, bakım ve su iletim, dağıtım ve uygulama randımanlarını su kullanım etkinliği göstergeleri olarak ele almışlardır. Su sağlanması göstergeleri içerisinde su dağııı oranı, su sağlama oranı; su kullanım göstergeleri içerisinde yeterlilik oranı, güvenirlik oranı, eşitlik oranı; bakım göstergeleri içerisinde fonksiyonel yapı oranı ve alet ekipman kullanımı oranı; su iletim, su dağıtım ve uygulama göstergeleri içerisinde ise proje randımanı, iletim randımanı, dağıtım randımanı ve su uygulama randımanına yer vermişlerdir.

Bu araştırma ile 2012-2016 yıllarında Aşağı Pasinler Sulama sahası için izleme ve değerlendirme çalışması yapılarak sistem performansının değerlendirilmesi, işletime ilişkin sorunların ortaya konularak sulama şebekesinin performansını etkileyen sorunlara ilişkin çözüm olabilecek önerilerde bulunulması amaçlanmıştır.

\section{Materyal ve Yöntem}

$\mathrm{Bu}$ araştırma 2012-2016 yıllarında DSİ tarafından yapılan ve Aras Sulama Birliği'nce işletilen Aşağı Pasinler Ovası sulama alanında sistem performansını değerlendirilmesi amacıyla yürütülmüştür. Araştırmaya konu Erzurum Aşağ Pasinler Ovası sulama şebekesi alanı brüt 4610 ha olup sulu tarım yapılabilen net alan 3900 hektardır. Proje alanı Köprüköy ilçesinin Pekecik, Yağan, Emreköy, Buğdaylı köyleri ile Horasan ilçesinin Kırkgözeler, Döllek, Çamurlu, Yüzören ve Kırık köyleri arazilerini kapsamaktadır. Bölgedeki tarım arazilerinin rakımı 1632 m’nin altındadır. Sulama suyu cazibe ile sağlanan proje alanında yüzey sulama yöntemleri kullanılmaktadır (Şekil 1). 
Horasan ve Köprüköy ilçelerini kapsayan araştırma alanında yıllık ortalama sıcaklık 6,9 $\mathrm{C}$, toplam yağış $445 \mathrm{~mm}$ ve ortalama bağıl nem ise \%71'dir. Yılın en kurak ayı $17 \mathrm{~mm}$ yağış ile Ağustos, en yağışlı ayı ise 67 mm ile Mayıs ayıdır. Y1llık buharlaşma $1059 \mathrm{~mm}$ olup en yüksek buharlaşma $222 \mathrm{~mm}$ ile Ağustos, en düşük buharlaşma ise $12 \mathrm{~mm}$ ile Ocak ayında görülmektedir (Anonim 2018).

Araştırma alanının yerüstü su kaynağını Aras nehri ve kolları oluşturmaktadır. Şebekeye sulama suyu sağlayan yapı Yataklar Regülatörüdür. Su alma yapısı üzerinde $4500 \mathrm{~L} / \mathrm{s}$ kapasiteli iki adet su alma prizi bulunmakta olup sulama mevsiminde ana kanala 3895 L/s su iletilmektedir (Anonim 1979). Aşağı Pasinler Regülatöründen alınan sulama suyu ile 3900 ha'lık alanı sulayan toplam 18 adet sekonder kanal, 34 adet tersiyer kanal ve ana kanal üzerinde 88 adet su alma yapisı mevcuttur.

Aşağı Pasinler Ovası arazilerindeki bitkisel üretim deseninin proje öncesi ve sonrası durumu Çizelge 1’de verilmiştir.

Çizelge 1. Sulama şebekesi yapımı öncesi bitki deseni ve proje öngörüleri

\begin{tabular}{lcc}
\hline Ürün & Proje Öncesi Durum (\%) & Proje Öngörüleri (\%) \\
\hline Buğday (sulu) & $4^{*}$ & 12 \\
Buğday (kuru) & 36 & - \\
Arpa (sulu) & $4^{*}$ & 8 \\
Arpa (kuru) & 12 & - \\
Yonca & $1^{*}$ & 30 \\
Çayır Üçgülü & $2^{*}$ & 2 \\
Şeker pancarı & $8^{*}$ & 15 \\
Fĭg & $2^{*}$ & - \\
Patates & $1^{*}$ & 6 \\
Soğan & - & 10 \\
Ayçiçeği & - & 5 \\
Bostan - Sebze & - & 10 \\
Silajlık Misır & - & - \\
Kavak & - & 2 \\
Nadas & 30 & - \\
\hline Toplam & 100 & 100 \\
\hline \multicolumn{2}{c}{}
\end{tabular}

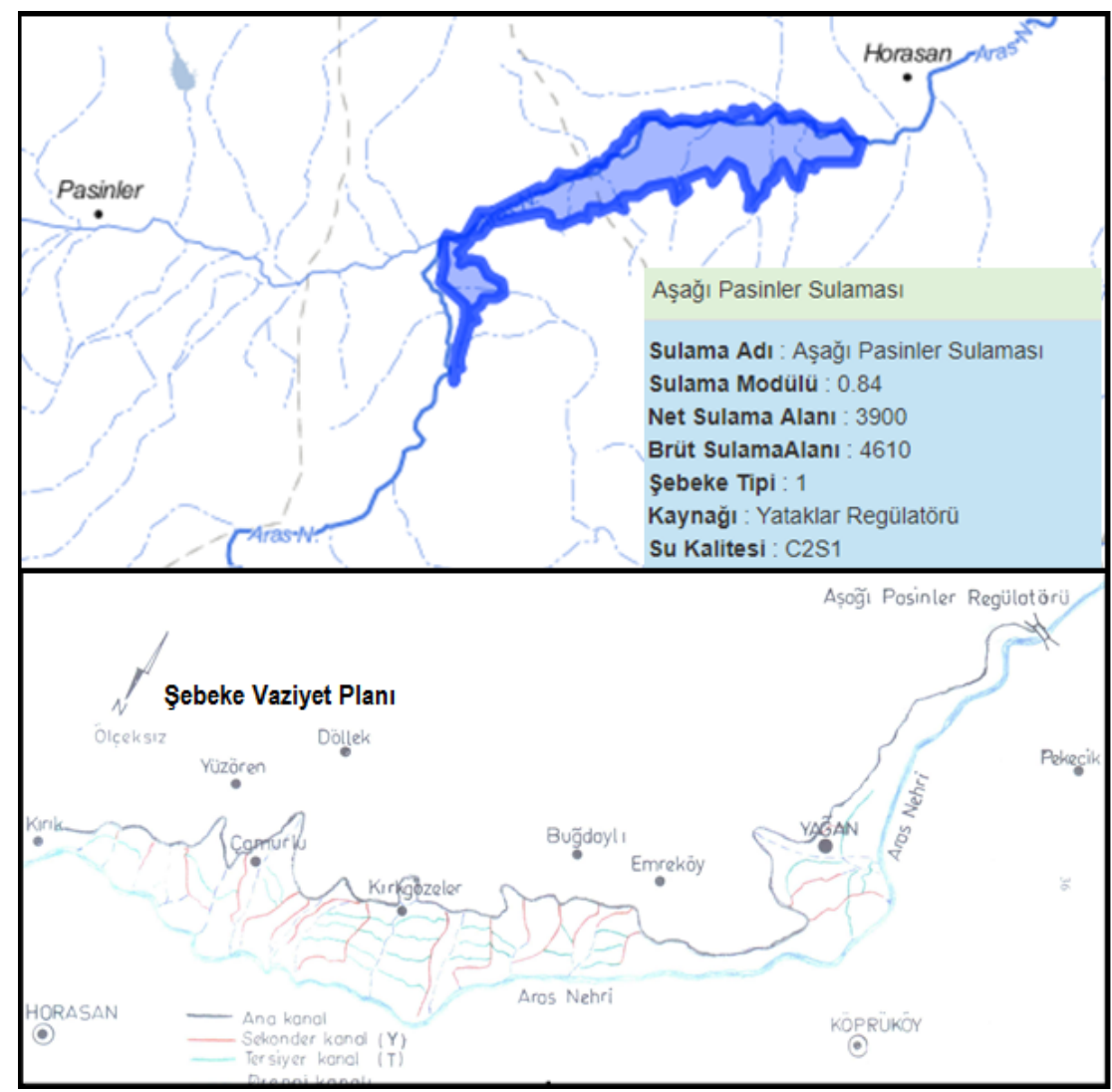

Şekil 1. Aşağ1 Pasinler Ovası Sulama Şebekesi. 
Sulama şebekelerinde izleme değerlendirmenin amacı; şebeke yeterliliğinin belirli ölçütlere göre tespit edilmesi, varsa sorunların belirlenmesi ve çözüm önerilerinin ortaya konulmasıdır. Bu ölçütler; suyun kaynaktan alınıp bitki kök bölgesinde depolanmasına kadar yapılan su iletim ve dağıtımında oluşan kayıp miktarlarını, sulanan alan ile bitkisel üretim aktivitelerini içeren tarımsal etkinlik göstergelerini, sürdürülebilir sulu tarım için hem su kullanımı hem de tarımsal girdilerin etkilerini inceleyen ekonomik, sosyal ve çevresel etkinlikleri kapsamaktadır.

Bu çalışmada; Aras Sulama Birliği sulama alanına ilişkin net su temin oranı $\left(\mathrm{STO}_{\mathrm{n}}\right)$, toplam su temin oranı $\left(\mathrm{STO}_{\mathrm{t}}\right)$, sulama oranı (SO), üretim değeri oranı (ÜDO), mali yeterlilik oranı (MYO), mali etkinlik oranı (MEO), tahsilat oranı (TO) ve karlılık oranı (KO); Benli ve Beyribey (1998), Beyribey ve Tatlıdil (1999)'in önerdikleri aşağıdaki eşitlikler yardımıyla belirlenmiştir. Hesaplamalarda DSİ kabulleri doğrultusunda toplam sulama randımanı \% 42.5 alınmıştır. Bu değer DSİ'nin devrettiği işletmelerdeki ortalama toplam randıman değerlerine yakın değerdir (Çakmak ve ark. 1999).

$$
\begin{array}{rlrl}
\text { STOn } & =\frac{\text { Sulama Alanına Saptırılan Su }}{\text { Net Sulama Suyu İhtiyacı }} & \text { MEO } & =\frac{\text { İşletme Bakım Masrafı }}{\text { Toplam İşletme Bakım Gereği }} \\
\text { STOt }=\frac{\text { Sulama Alanına Saptırılan Su }}{\text { Toplam Sulama Suyu İhtiyacı }} & \text { MYO }=\frac{\text { Tahakkuk }}{\text { Toplam İşletme Bakım Gereği }} \\
\text { SO }=\frac{\text { Sulanan Alan }}{\text { Sulama Alanı }} & \text { TO }=\frac{\text { Tahsilat }}{\text { Tahakkuk }} \\
\text { ÜDO }=\frac{\text { Gerçekleşen Üretim Değeri }}{\text { Planlanan Üretim Değeri }} & \text { KO }=\frac{\text { Sulama Suyu Faydası }}{\text { Yıllık Gider }}
\end{array}
$$

Araştırma alanında yetiştirilen bitkilerin bitki su tüketim değerleri yörede yapılan çalışmaların sonuçlarından (Kızıloğlu 2002) ve bitki su tüketimi rehberlerinden (Anonim 2016) alınmıştır.

\section{Bulgular ve Tartışma}

Araştırmaya konu sulama şebekesinde 2012-2016 yıllarında yetiştirilen ürünler ve bu ürünlerin yetiştirildiği alanların toplam sulanan alana oranlarını gösteren Çizelge 2'den de izlenebileceği gibi sulama şebekesinde bitkisel üretim yapılan arazi büyüklüğü 1000 ha ile 2000 ha arasındadır. Oysa sulamaya açılan alan net 3900 hektardır. Ana kanal güzergâhında meydana gelen heyelan ve göçükler nedeniyle arazinin önemli bir kısmına sulama suyu iletilememekte ve bu alanlarda sulu tarım yapılamamaktadır. Ana kanal bakım ve onarım işlerinin sözleşmeye de uygun olarak tesisi devreden kurum tarafından yapılması gerekir. Bu durum şebekede işletme ve bakım gereksinimini artırmakta olup bu kaynağın temin edilememesi nedeniyle şebekenin tamamında sulu tarım yapılamamaktadır.

Çizelge 2. Araştırmaya konu sulama şebekesinde 2012-2016 yıllarında sulu koşullarda yetiştirilen ürünler ve bu ürünlerin yetiștirildiği alan büyüklükleri

\begin{tabular}{lccccc}
\hline Yllar & $\mathbf{2 0 1 2}$ & $\mathbf{2 0 1 3}$ & $\mathbf{2 0 1 4}$ & $\mathbf{2 0 1 5}$ & $\mathbf{2 0 1 6}$ \\
\hline Buğday & \multicolumn{5}{c}{ Üretim alanı (ha) } \\
Arpa & 270 & 170 & 308 & 350 & 340 \\
Şeker Pancarı & 100 & 100 & 181 & 150 & 146 \\
Patates & 227 & 470 & 851 & 100 & 97 \\
Bostan & 48 & 15 & 27 & 60 & 58 \\
Ayçiçeği & 300 & 29 & 53 & 64 & 62 \\
Yonca & 10 & 250 & 453 & 200 & 194 \\
\hline Toplam & 45 & 70 & 127 & 140 & 136 \\
\hline
\end{tabular}

Şebekede net sulama alanı 3900 ha olup Çizelge 2'den de izlenebileceği gibi sulamaya açılan alanın tamamında alt yapı sorunları nedeniyle sulu tarım yapılamadığı ve Çizelge 1'de sunulan planlama öngörülerinin gerçekleştirilemediği görülmektedir. Çiftçi alışkanlıklarının değişmekle beraber üreticinin buğday, şeker pancarı ve ayçiçeği ağırlıklı deseni tercih ettiği görülmüştür. Planlama verilerine uyulamamasının temel nedeni, çiftçinin hayvancılığa dayalı bitkisel üretim tercihi, ürün girdilerinin yüksekliği, şebekede her kesime su sağlanmasındaki zorluklar, su fiyatlandırma politikaları, bölgeden olan yoğun göç ile çiftçinin geleneksel ürün desenini uygulama eğilimleri gösterilebilir. 
Sulama sezonu içerisindeki şebekeye saptırılan su miktarları, toplam ve net sulama suyu ihtiyacı ile toplam ve net su temin oranlarının aylık değişimleri Çizelge 3’te verilmiştir. Araştırma yallarında net su temin oranı 5.25 ile 10.68 arasında iken toplam su temin oranı 2.23 ile 4.54 arasındadır. Benli ve Beyribey (1998), toplam su temin oranının ideal olarak 1'e eşit olması gerektiğini, 1' den az olması durumunda saptırılan suyun yetersiz olduğunu, 1'den büyük olması durumunda ise gereksinimden daha fazla su saptırıldığını belirtmişlerdir. Beyribey (1997)'e göre sulama şebekelerinde net su temin oranının $2.5^{\prime}$ den büyük olması sulama alanında planlı su dağıtımının yapılmadığını veya yapılamadığını, toplam sulama randımanının düşük olduğunu göstermektedir. Bu verilere göre araştırma alanına saptırılan suyun gereksinimden daha fazla olduğu ve böylece proje alanı için sulama randımanının olumsuz yönde etkilendiği söylenebilir.

Çizelge 3. Sulama sezonu içerisindeki şebekeye saptırılan su miktarları, toplam ve net sulama suyu ihtiyacı ile toplam ve net su temin oranlarının değişimi

\begin{tabular}{|c|c|c|c|c|c|}
\hline Yillar & $\begin{array}{c}\text { Şebekeye Saptırılan Su } \\
\left(\mathrm{hm}^{3}\right)\end{array}$ & $\begin{array}{l}\text { Net Sulama Suyu } \\
\text { Ihtiyaci }\left(\mathbf{h m}^{3}\right)\end{array}$ & $\begin{array}{c}\text { Toplam Sulama } \\
\text { Suyu İhtiyacı }\left(\mathrm{hm}^{3}\right) \\
\end{array}$ & STO $_{n}$ & STO $_{t}$ \\
\hline 2012 & 37018 & 3466 & 8155 & 10.68 & 4.54 \\
\hline 2013 & 37018 & 3889 & 9151 & 9.52 & 4.05 \\
\hline 2014 & 37018 & 7045 & 16578 & 5.25 & 2.23 \\
\hline 2015 & 37018 & 3574 & 8409 & 10.36 & 4.40 \\
\hline 2016 & 37018 & 3473 & 8172 & 10.66 & 4.53 \\
\hline
\end{tabular}

Araştırma yılları için tarımsal etkinlik göstergelerinden olan sulama oranı ve üretim değeri oranları da incelenmiștir. Çizelge 4 'ten de izlenebileceği gibi proje sahasında sulama oranı \% 25.64 ile \% 51,28 arasında değişmektedir. Sulama şebekesinde düzenli olarak bakım ve onarımın gerçekleştirilmemesi, su iletim ve dağıtım sistemlerine ilişkin sorunlar şebekede her alana düzenli olarak sulama suyu dağıtımını güçleştirmektedir. Organizasyonla ilgili sorunların giderilmesi, bakım onarım çalışmalarının düzenli yapılması durumunda sulama alanın artırılmasıyla mevcut şebekeden elde edilen gelir DSİ planlama verilerine yaklaşacaktır.

Sulama şebekesinde üretim değeri oranları \% 15.20 ile \% 38.48 arasındadır. Sulama oranının düşük olması; ürün deseni seçiminde planlama kriterlerine uyulmaması, ürün girdi ve fiyatlarındaki dalgalanmalar bu değerin düşük olmasına neden olmuştur. Sulu tarıma geçişle birlikte çiftçi alışkanlıkları değişse de şebekedeki fiziksel sorunların çözümlenememesi üretim yapılan alanı daraltmıştır. Üretici pazar bulabildiği ürünlerin ekim alanlarını sabit tutarak diğerlerinin ekim alanlarını daraltmıştır.

Çizelge 4. Araştırma alanına ilişkin sulama oranı ve üretim değeri oranlarının değişimi

\begin{tabular}{cccccc}
\hline Veriler /Yıllar & $\mathbf{2 0 1 2}$ & $\mathbf{2 0 1 3}$ & $\mathbf{2 0 1 4}$ & $\mathbf{2 0 1 5}$ & $\mathbf{2 0 1 6}$ \\
\hline Sulanan Alan (ha) & 1000 & 1104 & 2000 & 1064 & 1034 \\
Sulama Alanı (ha) & 3900 & 3900 & 3900 & 3900 & 3900 \\
Gerçekleşen Üretim Değeri (TL) & 5089448 & 2144600 & 4127966 & 2974590 & 3051315 \\
Planlanan Üretim Değeri (TL) & 13226704 & 14108484 & 14990264 & 15872045 & 16753825 \\
Sulama Oranı (\%) & 25.64 & 28.31 & 51.28 & 27.28 & 26.51 \\
Üretim Değeri Oranı (\%) & 38.48 & 15.20 & 27.54 & 18.74 & 18.21 \\
\hline
\end{tabular}

Uluslararası Su Yönetimi Enstitüsü (IWMI) tarafından 1992 yılından itibaren dünyada 11 ülkede toplam 18 sulama sisteminde yürütülen çalışmalarda meyve, sebze ve endüstri bitkilerinin fazla olduğu sulama şebekelerinde elde edilen gelirin daha yüksek olduğu belirlenmiştir (Molden ve ark. 1998). Bölgede hububat ağırlıklı ürün deseninin seçilmesi üretim değeri oranını düşüren başka bir husustur.

Şebekenin sulama suyu faydası, yıllık giderler, işletme-bakım masrafları, toplam işletme bakım gereği, tahakkuk ve tahsilât miktarları ile hesaplanan karlılık oranı, mali etkinlik oranı, mali yeterlilik oranı ve tahsilât oranı Çizelge 5'te verilmiştir.

Tahsilat oranı değişim aralığı \% 29.7 ile \% 100.0 arasında olup şebekede en yüksek tahsilat oranı 2013 yılında, en düşük tahsilat ise 2014 ve 2015 yıllarında gerçekleşmiştir. Beyribey (1997) ülkemizde ortalama tahsilât oranının \% 97 olduğunu belirlemiştir. Araştırma alanı değeri Türkiye ortalamasının çok altındadır.

Çiftçinin katılımcı olduğu sulama birliklerinde su ücreti tahsilâtlarının zamanla artması ve bu değerin yükselmesi beklenmektedir. Tahsilâtın artırılabilmesi için birlik üyeleri arasında güven ortamının sağlanması, yaptırım gücü olan 
yasal uygulamaların işlevsel hale getirilmesi ve tahsilatın gerekliliği ve önemi ile ilgili eğitici çalışmaların artırılması gerekmektedir (Benli ve Beyribey 1998).

Çizelge 5. Ekonomik göstergelerin yıllara göre dağılımı

\begin{tabular}{llllll}
\hline Veriler/Yıllar & \multicolumn{1}{c}{$\mathbf{2 0 1 2}$} & \multicolumn{1}{c}{$\mathbf{2 0 1 3}$} & \multicolumn{1}{c}{$\mathbf{2 0 1 4}$} & $\mathbf{2 0 1 5}$ & $\mathbf{2 0 1 6}$ \\
\hline Sulama suyu faydası (TL) & 4012640 & 92540 & 2083141 & 531810 & 438621 \\
Yıllık gider (TL) & 430462 & 839548 & 852964 & 835331 & 976556 \\
İşletme - bakım masrafı (TL) & 3000 & 16450 & 158000 & 160000 & 160000 \\
Toplam işletme ve bakım gereği (TL) & 53000 & 129000 & 180870 & 193600 & 188600 \\
Tahakkuk (TL) & 250000 & 123470 & 655000 & 655000 & 660000 \\
Tahsilât (TL) & 125000 & 123470 & 194547 & 194547 & 300000 \\
Tahsilat oranı (\%) & 50.0 & 100 & 29.7 & 29.7 & 45.45 \\
Karlılık oranı & 9.32 & -0.11 & 2.44 & 0.64 & 0.45 \\
Mali etkinlik oranı (\%) & 5.66 & 12.75 & 87.36 & 82.64 & 84.84 \\
Mali yeterlilik oranı (\%) & 4.72 & 0.96 & 3.62 & 3.38 & 3.50 \\
\hline
\end{tabular}

Ülkemizde sulama şebekelerine ilişkin karlılık oranı 1.6 ile 5.7 arasında değişmekte olup ortalama değeri 4'tür. Sulama ile birlikte çağdaş tarım teknolojileri ve ucuz girdi kullanılması durumunda bu değerin 10-15 arasında olması olasıdır (Kızıloğlu 2002). Araştırma alanı için ortalama karlılık oranı - 0.11 ile 9.32 arasında olup ortalama 2.55 değeri ile ülkemiz ortalamasının altındadır. Mali etkinlik düzeyinde hesaplamış performans gösterge değerleri \% 5.66 ile \% 87.36 arasında olup ortalama \%54.65'tir. Beyribey ve Tatlıdil (1999)'e göre DSİ sulamaları mali etkinlik ortalaması \% 32'dir. Benli ve Beyribey (1998), Eskişehir sağ sahil sulama sistemi için mali etkinlik oranını \% 92 olarak belirlemişlerdir. Bu değerle kıyaslandığında proje alanında gerçekleşen mali etkinlik oranının yetersiz, ancak ülke ortalaması ile kıyaslandığında da daha iyi olduğu söylenebilir.

Sulama şebekelerinde her yıl tahakkuk ettirilen sulama suyu ücretlerinin gereksinim duyulan işletme bakım giderlerini karşılayıp karşılayamayacağını belirlemek amacıyla mali yeterlilik düzeyinde hesaplamış performans gösterge değerleri \% 0.96 ile \% 4.72 arasında olup ülke ortalaması \% 3.24’tür.

\section{Sonuç}

Erzurum Aşağı Pasinler Ovası sulama şebekesinin araştırma yıllarında performansını değerlendirmek amacıyla net ve toplam su temin oranları, sulama oranı, mali etkinlik oranı, mali yeterlilik oranı, tahsilât oranı, karlılık oranı ve üretim değeri oranı incelenmiş, bu göstergelerin birçoğunda şebeke verilerinin istenilen düzeyde olmadığı görülmüsstür.

Net ve toplam su temin oranları bakımından şebekenin sulama suyundan yeterli oranda yararlanılamadığı görülmüştür. Sulama oranının düşük oluşunun temel sebebi, şebekenin bakım onarım hizmetlerinin yetersiz olması, sekonder ve tersiyer kanalların tamamına su iletiminin gerçekleştirilememesidir. Bölgede ayçiçeği, şeker pancarı ve hububata dayalı yetiştiricilik yapılmasının ve yem bitkisi üretim alanının daralmasının nedeni ise şebeke sorunlarına dayalı sulama oranı düşüklügüdür. Şebekede bakım onarım çalışmalarının tamamlanarak şebekenin tamamında sulu tarım yapılmasıyla bu parametrelerinin tamamının değişmesi olasıdır. Şebekedeki fiziksel sorunlar giderilmeden bitkisel üretimde yeterli düzeye ulaşılması, ekonomik parametrelerin iyileşmesi ve sulama oranının artırılabilmesi mümkün gözükmemektedir.

Araştırılan şebekeye ilişkin sorunların çözümünden sonra çiftçi eğilimleri ve pazar koşullarına uygun ürün deseni, yönetici ve çiftçilere yönelik eğitim-yayım çalışmalarının planlanmalıdır. Ayrıca yeni sulama yöntemleri ve teknolojileri kullanımının desteklenmesi, teknik personele ve üreticilere eğitim verilmesi sulama suyu etkinliğinin artırımı için yarar sağlayacaktır.

\section{Kaynaklar}

Anonim (1979). Erzurum Projesi Yapılabilirlik Raporu. DSİ VIII. Bölge Müdürlüğü, Erzurum.

Anonim (2016). Türkiye'de Sulanan Bitkilerin Su Tüketimleri Rehberi. Tarımsal Araştırmalar ve Politikaları Genel Müdürlüğü, Ankara.

Anonim (2018). Devlet Meteoroloji İşleri Genel Müdürlüğü, Erzurum Bölge Müdürlüğü İklim Verileri, https://mgm.gov.tr/veridegerlendirme/il-ve-ilceler-istatistik.aspx?k

Benli B, Beyribey M (1998). Eskişehir sulaması sağ sahil sulama alanında sistem performansının değerlendirilmesi. Ankara Üniv. Ziraat Fak. Dergisi, 1(4):26-32.

Beyribey M (1989). Konya-Alakova yeraltısuyu işletmesinde su dağıtım ve kullanım etkinliği. Doktora Tezi, Ankara Üniversitesi, Fen Bilimleri Enstitüsü, Ankara. 
Beyribey M, Balaban A, Çakmak B, Oğuz M (1995). Devlet sulama şebekelerinde izleme ve değerlendirme. V. Ulusal Kültürteknik Kongresi, Kemer-Antalya, s:143-151.

Beyribey M (1997). Devlet Sulama Şebekelerinde Sistem Performansının Değerlendirilmesi. Ankara Üniversitesi Ziraat Fakültesi Yayınları No: 1480, Ankara.

Beyribey M, Tatlıdil FF (1997). Ereğli ilçesi İvriz Sağ Sahil Sulama Birliği'nde sulama sistem performansının değerlendirilmesi. Ziraat Dünyası, Türkiye Ziraatçılar Der., 448:28-32.

Beyribey M, Tatlıdil FF (1999). Ereğli İvriz Sağ Sahil Sulama Birliğinde Sulama Sistem Performansının Değerlendirilmesi, Ziraat Dünyası, Türkiye Ziraatçılar Derneği, Sayı: 448, s. 28-32, Ankara.

Çakmak B (1994). Konya Çumra sulamasında su dağıtım ve kullanım etkinliği. Doktora Tezi, Ankara Üniversitesi Fen Bilimleri Enstitüsü, Ankara.

Çakmak B, Tanrıvermiş H, Benli B (1999). Türkiye’ de sulama ve tarımsal kalkınma. VII. Kültürteknik Kongresi, 1114 Kasım 1999, Kapadokya-Nevşehir, s:17-26.

Değirmenci H (2004). Kahramanmaraş bölgesinde bazı sulama şebekelerinin karşılaştırma göstergeleri ile değerlendirilmesi. KSÜ Fen ve Mühendislik Dergisi, 7(1):104-110.

Delibaş L (1992). Büyük sulama şebekelerinde optimum planlama ve yönetimi. IV. Ulusal Tarımsal Yapılar ve Sulama Kongresi, 24-26 Haziran 1992, Erzurum, s:25-35.

Kızıloğlu FM (2002). Aşağı Pasinler ovası sulama sisteminin performansı, sorunları ve çözüm önerileri üzerine bir araştırma. Doktora Tezi, Atatürk Üniversitesi, Fen Bilimleri Enstitüsü, Erzurum.

Kocabaş ES, Girgin İ (1998). Sulama şebekelerinde sistem performansının değerlendirilmesi. Tarım Bilimleri Dergisi, 4(2):39-48.

Moden DJ, Gates TK (1990). Performance measures for evaluation of irrigation water delivery systems. J. Irrig. Drain. Eng, 166(6):804-823.

Molden DJ, Sakthivadivel R, Perry CJ, Fraiture C, Klozen WH (1998). Indicators for comparing performance of irrigated agricultural systems. IWMI Research Report 20, Sri Lanka.

Rao PS (1993). Review of selected literature on indicators of irrigation performance. International Irrigation Management Institute, Colombo, Sri Lanka, s:1-75.

Uçar Y (2011). Performance assessment irrigation schemes according to comparative indicators: A case study of Isparta, Turkey. European Journal of Scientific Research, 52(1), 82-90. 